\title{
Analysis of Chinese Grain Total Factor Productivity Based on DEA- Malmquist Index Method
}

\author{
Yue Hui ${ }^{1, a}$ \\ ${ }^{1}$ Emerging Economic Formats Research Institute of Shandong Management University, Jinan City, \\ Shandong Province, 250100 \\ a1627226202@qq.com
}

Key words: Grain, Total Factor Productivity, DEA-Malmquist Index Method

\begin{abstract}
In the context of agricultural big data, production efficiency not only reflects the efficiency of agricultural products competitiveness and resource allocation, but is regarded as an important indicator of industrial development prospects. Based on the data of Chinese grain production input and output from 1978 to 2018, by using the DEA-based nonparametric productivity index method, the paper finds out the fact that the growth tendency of food total factor productivity is mainly negative $(68.75 \%)$. Specifically, the change of technical efficiency (Efch) and the scale efficiency index (Sech) are highly convergent, reaching the highest value in the policy implementation year of 2004-2005; the changes of Technology Progress Index (Tech) and TFP are highly convergent as well. The change of TFP is mainly affected by the Technology Progress Index (Tech), and the wheat and corn input factors are redundant. Based on the above research, the technology progress index of soybean and rice is the key to lowering the total factor productivity of China's grain. Redundancy of wheat and corn production resources is the key to the low efficiency of grain and grain production in China. Therefore, the focus of improving China's grain total factor productivity is to improve the technological progress of soybeans and rice, increase the utilization rate of wheat and corn resources, and adapt China's food security production to an unstable agricultural product trade policy.
\end{abstract}

\section{Introduction}

Food production is resource-constrained. The production link is the constraint of the element resource and the essential constraints are the input of key elements such as land, water resources, labor and technology. With the development of industrialization 、 urbanization and rural revitalization, the above-mentioned resources have become the core constraints of food security in the new era, and this constraint has an increasing trend. In 2018, the No. 1 Document of the Central Committee proposed to improve the quality of agricultural development and cultivate new kinetic energy for rural development; Improving quality of agricultural development and promoting agricultural prosperity must increase agricultural innovation, competitiveness and total factor productivity $^{[1]}$. For the purpose of improving food production efficiency, based on the calculation of grain production efficiency in China from 1978 to 2018,this paper uses DEA(Data Envelopment Analysis) Malmquist index method and analyze the changing trend of Chinese grain production efficiency, then give countermeasures and suggestions for adapting to food safety production under the background of big data agriculture ${ }^{[2]}$.

\section{Theoretical basis}

According to the theoretical principle of the DEA, the article selects the input and output of the four major grain including rice, wheat, corn and soybean production in 32 years as the research object. Each object has 3 inputs, 1 output. Output indicators select the output per unit area of grain, and the input indicators are direct cost, indirect cost, and labor cost indicators as shown in Table 1 below. 
Table 1 China's grain production input and output indicators

\begin{tabular}{cl}
\hline output & Grain yield per unit area $(\mathrm{kg} / \mathrm{mu})$ \\
\hline \multirow{3}{*}{ Input } & Direct cost (Yuan $/ \mathrm{ha})$ \\
& Indirect costs (Yuan/ha) \\
& Labor cost (Yuan/ha) \\
\hline
\end{tabular}

Source: China National Development and Reform Commission

\section{Total Factor Productivity Measurement and Result Analysis}

Using DEAP 2.1 software, the output-oriented DEA-Malmquist index method was used to measure the output-oriented food production efficiency from 1978 to 2018. Efch is the technical efficiency change index. Tech is the technology progress index. Pech is the pure technical efficiency change index. Sech is the scale efficiency change index. TFP is the total factor productivity index.

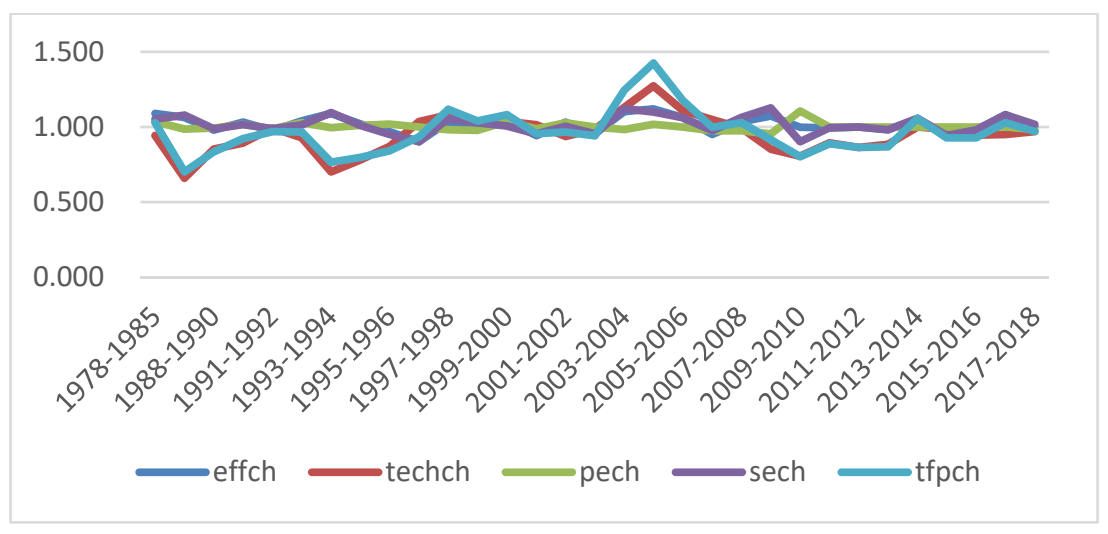

Fig. 1 Trends in China's grain total factor productivity index

As can be seen from Figure 1, TFP fluctuated greatly from 1978 to 2018. From 1978 to 1998, total factor productivity was in a period of negative growth, only 10 of the 32 analysis years were at a positive growth of 1 or more. From 2004 to 2005, the fluctuation of the highest point of 1.425 was obvious, and the multi-period was in a negative growth state. The change in technical efficiency (Efch) is highly convergent with the change of the scale efficiency index (Sech), which reached its highest value in 2004-2005. The Technology Progress Index (Tech) and the TFP change are highly convergent and TFP changes are mainly influenced by the Technology Progress Index (Tech).

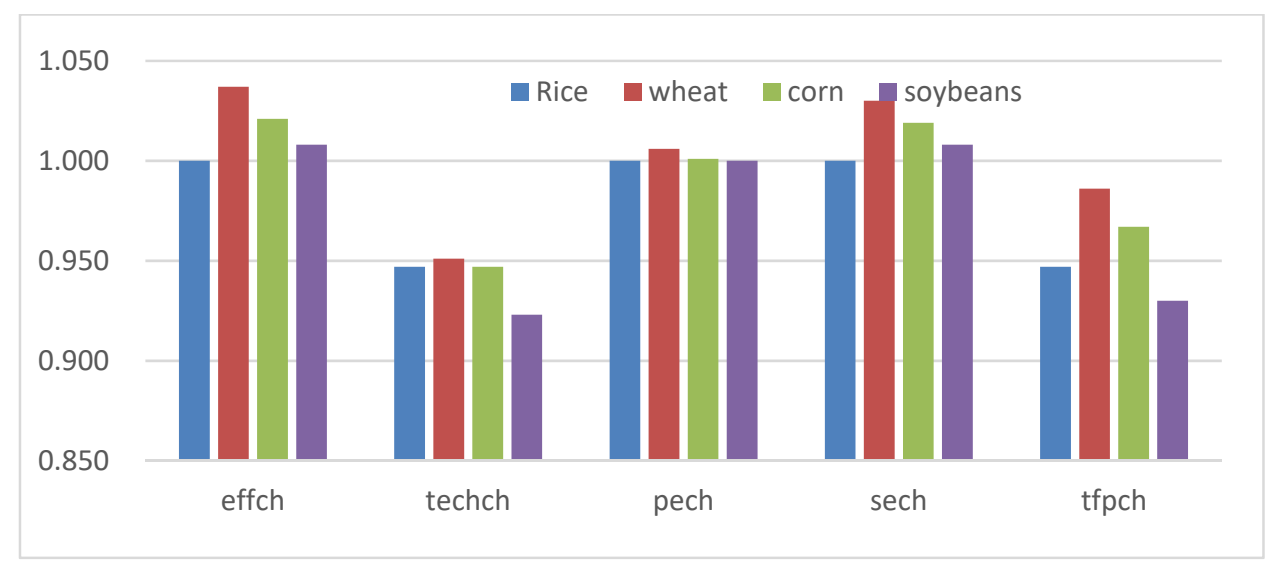

Fig. 2 Changes in the efficiency of the four major foods in 1978-2018

As can be seen from Figure 2, the TFP of Chinese four major grain are ranked in order wheat, corn, rice, and soybean from high to low. Specifically, rice and soybeans are lower than the average level 
of grain TFP in China. The four major food crop technology advancement indices (Tech) are at low level, which is the main reason for lowering total factor productivity. The technological progress index of Soybean and low total factor productivity are the main aspects that undermine Chinese grain total factor productivity. Besides, the total factor productivity of rice is low.

\section{Conclusion and recommendations}

In the process of transforming the industrial economy into the knowledge economy, transforming Chinese grain transform to meet the requirements of the development of the new era is important. In view of the instability of Chinese grain total factor productivity, the differences between varieties, and the average total factor productivity of grain are at a low level. Certain policy measures should be taken to adapt Chinese grain products to market economy requirements and achieve optimal resource allocation.

\subsection{Main conclusion}

TFP fluctuated greatly from 1978 to 2018, In 1978-1998, TFP was in a period of negative growth, and only 10 of the 32 analysis years were in positive growth. From 2004 to 2005, the fluctuation of the highest point of 1.425 was obvious, and the multi-period was in a negative growth state. The annual decline in the Technology Progress Index (Tech) is the dominant factor in the decline of total factor productivity. Technological progress is the key to the improvement of TFP. The optimal allocation of resources should start with technological advancement. In 2004, Chinese grain circulation system reform had a large impact on the above-mentioned indicators in the current period. Besides, From 1978 to 2018, the TFP of Chinese four major grain are ranked in order wheat, corn, rice, and soybean from high to low. Rice and soybeans were lower than average Chinese grain total factor productivity. Production technology efficiency and scale efficiency perform better than other indicators, and production technology efficiency is the main reason for promoting total factor productivity. The four major food crop technology advancement index (Tech) are at a low level, which is the main reason for lowering total factor productivity. Among them, the soybean and rice technology progress index are the keys to lowering the total factor productivity of Chinese grain.

\subsection{Recommendation}

Accelerating the whole process of mechanized production of grain and improving the level of production technology are important. The analysis of food production efficiency shows that the efficiency level of grain production technology has a greater impact on TFP. Improving technical efficiency can increase production efficiency. It is important to focus on the improvement of production technology of soybeans and rice, increase scientific and technological input in the production of two crops, increase the cultivation of new varieties of grain, improve production technology and production efficiency and profitability ${ }^{[3]}$.

Accelerating the reform of the grain production and marketing system and improving the policy effect are important. The analysis of grain total factor productivity shows that the period of better indicator performance happens to be the year of policy introduction ${ }^{[4]}$, In the year of reform of the grain circulation system, the TFP was the highest. The effectiveness of the policy in China is more effective than other technologies.

Improving food production mode and achieving optimal resource allocation are necessary. Smallscale production of grain is no longer suitable for modern production requirements, so improving production mode and carrying out large-scale farm production is beneficial to the development requirements of the industry ${ }^{[5]}$. Promoting the deep integration of the industrial chain with modern technology to achieve optimal allocation of resources in the industrial chain is important. 


\section{Acknowledgment}

This research was financially supported by the National Social Science Fund Key Project "Accelerating the construction of agricultural waste resource utilization policy research"(17AD012)、 Shandong Provincial Social Science Planning Research Project "Evaluation of the implementation effect of agricultural products geographical indications in Shandong Province based on rural revitalization in the construction of three major agricultural systems" (18CCXJ04) 、Shandong Provincial Department of Education, Higher Education Research and Development General Project "Study on the Demonstration Effect of Geographical Indications of Agricultural Products in Shandong Province in the Construction of Modern Agricultural System" (J17RA093) Co-finance.

\section{References}

[1] O' Donnell C J. An aggregate quantity- price framework for measuring and decomposing productivity change [R]. Centre for Efficiency and productivity analysis working paper, 2008.

[2] Lu Na, Zhu Lizhi. Research on the Efficiency of Agricultural Environmental Technology and the Growth of Green Total Factor Productivity in China[J]. Agricultural technology economy,2019(04):95-103.

[3] Zhang Li, Tong Zhou. The Influence of High-tech Industry Cluster of "One Belt and One Road" on Total Factor Productivity[J]. Journal of Xi'an University of Posts and Telecommunications,2018,23(02):95-101.

[4] Huang Xianhai, Jin Zecheng, Yu Linhui. Factor Flow and Total Factor Productivity Growth: Empirical Evidence from State-owned Sector Reform[J]. Economic Research, 2017, 52(12): 6275.

[5] JI Jin-peng, SONG Xiao-hong. An Empirical Analysis of Factors Affecting Grain Total Factor Productivity[J]. Statistics \& Decision,2015(11):126-129. 